perilously near the healthy eyes of another person. Comment is needless; other diseases may possibly be conveyed in similar manner. Can nothing be done to suppress this dangerous nuisance?

I am, Sirs, yours faithfully,

ARthur J. Harries, M.D. Brux.

Adam-street, W.C., Oct. 30tb, 1900.

\section{TENDER FOR CONTRACT BY MEDICAL MEN.}

To the Editors of THE LANCET.

SiRs,-I enclose copy of letter received from the Castleford Urban District Council about attendance on cases at the infectious hospital, and I should be grateful for your opinion on the matter. Hitberto it has been the custom for each medical man to attend his own patients at the hospital and to make his own charges to the council. Personally, I feel it would be an unprofessional act to "tender" for an appointment in this way, and I propose to write to the council to this effect. I am, Sirs, yours faithfully,

Castleford, Oct. 30th, 1900 .

W. KEMP, M.B. Edin.

[Copr.]

Urban District Council Offices, Castleford, Yorks, Oct. $29 \mathrm{th}, 1900$.

Re.Cases at the Infectious Hospital

DEAR SIR, - I am instructed by this council to state that, in their opinion, the attendance of different medical practitioners at the hospital is, on several grounds, inadvisable, and that it would be better if one medical gentleman alone had the cases in hand, the council being held responsible for the payment of fees in such cases. If, however, the they will be at liberty to do so, they paying his fees; and I am to ask you if you will kindly give us your terms, including medicine and attendance, for cases of infectious diseases at the hospital.- Your faithfully.

Dr. W. Kemp, Castleford.

** The medical men of the district should meet and agree upon the course to be pursued. In this way a decision will be arrived at that is best for the community. We do not think it well that medical men should tender for contracts, and we are certain that where this method is employed the public will be badly served.-ED. L.

\section{"ORTHOPTIC TREATMENT OF CONVERGENT SQUINT IN YOUNG CHILDREN": A CORRECTION.}

To the Editors of THE LANCET.

Sins, - Will you kindly allow me to correct one or two errors in your notice of the paper read by me at the last meeting of the Ophthalmological Society ? ${ }^{1}$ The report says "Mr. Worth ...... commonly commenced treatment as follows." This should be : "Treatment adopted by most surgeons was as follows." Again, "The visual acuity of the child's squinting eye was obtained." It will naturally occur to an yone that these small children cannot read Snellen's types. It should have been mentioned that I described a method by which the visual acuity might be ascertained. The report says : "Mr. Worth had found that this treatment in some hundreds of cases caused a disappearance of the squint, \&c." What I said was that I had carried out the treatment in some hundreds of cases and in a considerable proportion it had caused a disappearance of the squint, \&c. Harley-street, w. I am, Sirs, yours faithfully,

$*_{*}^{*}$ We regret the inaccuracy of the report.-ED. L.

\section{THE MEDICAL DIRECTORY FOR 1901.}

\section{To the Editors of THE LANCET.}

Sirs, - You have frequently been good enough to refer in your columns to the accuracy of the Medical Directory. As you are aware the Directory cannot be up-to-date unless all the members of the profession and the secretaries of medical institutions respond to the editors' requests for information. All persons interested must now communicate with the editors at once, for in a few days it will be too late to attend to any further alterations.

We are, Sirs, your obedient servants,

Great Marlborough-street, W., Oct. 22nd, 1900. J. \& A. Churchill.

\section{THE TEACHING OF HISTOLOGY, ETC., AT ST. ANDREWS UNIVERSITY.}

\section{To the Editors of THE LANCET.}

Sins, - I would like to point out a slight inaccuracy, or rather omission, which occurs in your table of classes on page 689 of THE LANCET of Sept. 1st, 1900, which has been brought under my notice. It would appear from this list that I only teach in summer and do not teach histology. I give in winter (1) a full junior course of 100 meetings, (2) a senior (lecture) course of 40 to 50 meetings, and (3) a senior practical course of 50 meetings; and in summer (1) a course of 50 meetings of histology and physiological chemistry and (2) lectures on development and reproduction (see pages 164166, Calendar, 1900-1901, St. Andrews University). I think your otherwise excellent list hardly represents my classes correctly. I am, Sirs, yours faithfully,

University of St. Andrews, Oct. 23rd, 1900 D. FraSer Harris.

\section{"THE SPAS OF CENTRAL WALES." \\ To the Editors of THE LANCET.}

SIRS,-I am sure that much real good would be done and much valuable instruction gained in the field of hydrotherapeutics if the excellent suggestion of $\mathrm{Mr}$. T. Garrett Horder in THE LANCET of Oct. 20th (p. 1176) could be carried out. I am pretty certain that the majority of our profession are quite ignorant of the sound inducements which are offered by our spas at home. These spas would become better known to the profession and their merits could be sifted therapeutically if the Balneological Society would adopt the suggestion of Mr. Garrett Horder and visit the various spas in this country. He speaks of the beauties of Central Wales and the remarkably bracing effects of the beautiful elevations of that district. He did not speak of the medicinal value of the waters found there. Yet if he will refer to the analyses of these waters and to the clinical records concerning them he will find that we possess near at hand means not excelled by those of any Continental resort of treating patients by a course of waters internally and externally. In the district of which he speaks there are three more or less well-known spas-namely, Llandrindod, Llangammarch, and Llanwrtyd. The first has its sulphur and saline springs, the second its barium and saline waters, and the third its waters like Harrogate. Llangam march is right in the centre of this beautiful elevated district; it is charmingly situated and enjoys most invigorating air. The hotel is high up and just under the imposing shelter of the Eppynt range (1800 feet). In the British Medical Journal of Oct. 20th Dr. Robert Saundby, speaking of Llandrindod, which is close to Llangammarch but not so prettily situated, says that it owes more to its altitude and climate than to the waters, and on this account is so satisfactory in the treatment of nervous exhaustion, dyspepsia, and gout. Quite recently you, Sirs, drew our attention to the iron waters of Shanklin Spa, and at the risk of trespassing on your space I cannot help repeating the valuable opening remarks you made in that article. "In spite of representations to the contrary English people still visit the various spas of the continent, whatever may be the advantages which may be had at similar places in this country. Fashion is doubtless the chief factor which has hitherto been unfavourable to enterprise in regard to the development of English spas. Yet if a list of the natural springs of Great Britain be consulted it will be found that almost all kinds of mineral waters occur in this country. We have thermal baths at Bath, sulphur waters at Harrogate and Llanwrtyd in Wales, and saline springs and barium springs in Wales, not to speak of the chalybeate springs at Tunbridge Wells, Brighton, and elsewhere. In some instances, of course, great efforts have been made to equip these places on a scale similar to Homburg, Wiesbaden, and Schwalbach on the continent, but our home resorts do not possess the renown of the foreign 